\title{
JUVENTUDES E ENSINO DE GEOGRAFIA
}

\author{
Youth and Geography Teaching
}

\author{
Shirley Alves Viana Vanderlei* \\ Carolina Machado Rocha Busch Pereira**
}

* Mestre em Geografia pelo PPG em Geografia da UFT - shirleyviana@ifto.edu.br. ** Docente do PPG em Geografia da UFT - carolinamachado@uft.edu.br.

Recebido em 09/08/2018. Aceito para publicação em 25/08/2018.

Versão online publicada em 20/11/2018 (http://seer.ufrgs.br/paraonde)

\begin{abstract}
Resumo: 0 artigo aborda a categoria juventude e sua relação com o ensino de Geografia. Os jovens contemporâneos, possuem características diversas que ao vivenciarem, procuram uma identificação. Sabe-se que o ensino de Geografia pode contribuir de forma significativa para o processo de aprendizagem da educação geográfica e também de leitura de mundo, quando o professor procura fazer uma interação entre o conhecimento prévio dos alunos e o conhecimento científico e geográfico. É necessário um aprofundamento nos debates sobre a temática Geografia e juventude sobre tudo por se tratar dos sujeitos que estão na escola e que participam das aulas. Portanto, buscou-se uma reflexão teórica inicial através de meios impressos e digitais, sobre os jovens contemporâneos e suas relações com o ensino de Geografia e como esta pode contribuir para a formação cidadã desses sujeitos.
\end{abstract}

Palavras-chave: juventudes; professor; ensino de Geografia.

Abstract: The article addresses the youth category and its relation with the teaching of Geography. Contemporary young people have different characteristics that when they experience, seek identification. It is known that the teaching of Geography may significantly contribute, when the teacher seeks to know his student and from there, seeks to make an interaction between the students' prior knowledge and the scientific knowledge of the teacher. It is necessary to deepen the debates on the subject in research. Therefore, we sought an initial theoretical reflection through print and digital media, on contemporary young people and their relations with the teaching of Geography and how it, can contribute to the citizen formation of these individuals. Key-words: youth; teacher; Geography teaching.

\section{Introdução}

O trabalho propõe a investigação sobre os sentidos que os jovens alunos da Educação Profissional Integrada ao Ensino Médio do Instituto Federal do Tocantins - Campus de Porto Nacional atribuem ao ensino de Geografia. A juventude na contemporaneidade se mostra diversificada em função do contexto social repleto de transformações, principalmente no que diz respeito ao acesso à informação. Para Cassab (2015, p. 139), "não existe apenas um tipo de juventude, mas juventudes, que assumem diferentes expressões de acordo com as condições culturais e materiais que as rodeiam". Daí a importância de se conhecer quem são esses jovens e o que a disciplina de Geografia tem significado para eles.

A Geografia, tanto a acadêmica, quanto a escolar se institucionalizou no Brasil no início do século XX, por meio da Sociedade Brasileira de Geografia (SBG), o Instituto Brasileiro de Geografia e Estatística (IBGE), Universidade de São Paulo (USP) e outras instituições, no entanto, a história dessa disciplina apresenta que antes mesmo de se constituir como campo de formação ela já era ensinada nas escolas. Mas, na década de 80 surge um movimento da Geografia que buscava uma renovação (movimento de renovação da Geografia) com o objetivo de superar a Geografia dita Tradicional (CAVALCANTI, 2008).

Ainda de acordo com Cavalcanti (2008, p. 23) "a busca por esses novos caminhos igualmente faz parte da história da geografia escolar". Essa busca é mediada pelos problemas enfrentados pela Geografia (tradicional), na qual a forma como era ensinada não atraía os alunos (devido o ensino 
pautado na memorização) e não apresentava nenhum significado servindo apenas como sentimento de patriotismo. Daí a preocupação em ensinar uma Geografia que se apresente de forma significativa para o aluno; que a torne atrativa e viabilize o aprendizado.

Qualquer ação que envolve o processo de ensino/aprendizagem requer responsabilidade, dedicação e principalmente o domínio do campo do saber por parte dos professores. Portanto, ressalta-se a importância de uma discussão aprofundada sobre o tema em questão.

Vale ressaltar que este trabalho, faz parte da primeira etapa da execução do projeto de pesquisa de mestrado, portanto, possui cunho estritamente teórico e para a sua realização buscou-se materiais sobre o assunto em meios impressos e digitais.

Quanto ao espaço da pesquisa, foi escolhido o Campus de Porto Nacional do Instituto Federal de Educação, Ciência e Tecnologia do Tocantins. A cidade de Porto Nacional localiza-se a 64 km de Palmas (capital do estado), ligando-se a ela pelas TO 050 e 070. Ocupa localização estratégica para a Hidrovia Araguaia/Tocantins e para a Ferrovia Norte/Sul e pela estratégica localização no estado tem assistido ao crescente aumento populacional e ao aumento da dinâmica regional pautada em grande parte pelo agronegócio.

\section{Desenvolvimento}

Ao propor investigar a relação que os jovens contemporâneos estabelecem com o ensino de Geografia faz-se necessário, primeiramente, conhecer esses jovens que chegam nas escolas e adentram as salas de aulas. No entanto, nos cabe alguns questionamentos: Quem são esses jovens? Que significados têm para eles a Geografia que estudam?

Antes de responder aos questionamentos, é importante explicitar os diversos conceitos que são apresentados sobre a categoria juventude. Cassab (2011), apresenta três possíveis acepções que norteiam o conceito de juventude: a) recorte etário - entre 15 - 24 anos, definido pela Organização Mundial da Saúde (OMS); b) uma transição - passagem da infância à vida adulta e c) juventude associada a um eterno devir, a um projeto futuro, que portanto, nega o presente.

Kehl (2004, p. 89-90), afirma que "a juventude é um estado de espírito, é um jeito de corpo, é um sinal de saúde e disposição, é um perfil de consumidor, uma fatia do mercado onde todos querem se incluir". Nos dias atuais, quem não quer ser considerado jovem? Assim, é uma constante a busca por uma juventude longa.

Dayrell (2003), argumenta que não é fácil construir uma definição da categoria juventude, pois os critérios que a constituem são históricos e culturais. Faz ainda uma alerta aos pesquisadores, quando realizar análises sobre as diversas imagens a respeito da juventude, não analisar os jovens de forma negativa, principalmente ao enfatizar as características que lhes faltariam para corresponder a um determinado modelo de ser jovem. Assim, há um grande risco de não apreender os modos pelos quais os jovens, principalmente os das camadas populares, constroem suas experiências.

É notório que o conceito de juventude é amplo e diverso, pois assim como a vida, ela está inserida em um quadro de valores culturais e sociais que mudam ao longo do tempo, portanto, cada época a trata de forma diferente.

Sobre os jovens contemporâneos, Cavalcanti (2012), aponta algumas características que podem ser definidas a partir de análises de outros profissionais como psicólogos, psicanalistas, educadores, sociólogos de acordo com os seguintes aspectos: domínio com os meios de comunicação e informação; atraídos por imagens e movimentos; altamente consumistas; valorização do prazer individual e imediato; individualista; valorizam a liberdade e são inseguros em relação ao futuro.

É importante ressaltar que essas são apenas algumas características, entre outras, que os jovens vivenciam em busca de uma identificação. Segundo Cavalcanti (2012, p. 115), "esses sujeitos sociais vivem seu dia a dia na busca de identificação, baseados em sentimentos de pertencimentos e de afeto nos grupos dos quais participam e na constituição de redes em suas práticas cotidianas".

No trabalho docente cotidiano, é importante, que o professor conheça seu alunado, e no caso específico do professor de Geografia, os ajude a compreender suas práticas espaciais, que são produtoras de Geografia. Cavalcanti (2015, p. 13), afirma que "conhecer o aluno e, nesse caso específico, os jovens escolares, deveria ser uma preocupação central de qualquer professor". Para

Para0nde!?, Porto Alegre, v.10, n.2, p.103-110, 2018. Edição Especial com artigos publicados originalmente na XII ENANPEGE http://seer.ufrgs.br/paraonde 
Oliveira (2015, p. 28) "mais que simplesmente 'dar aula', é necessário dialogar com o jovem, ouvi-lo, escutá-lo, estar atento ao que vem falando, como vem se portando e as suas preocupações".

Para entender esse jovem aluno do ensino médio, as Diretrizes Curriculares Nacionais (2013, p. 155) afirma que "é necessário superar uma noção homogeneizante e neutralizada desse estudante, passando a percebê-lo como sujeito com valores, comportamentos e visões de mundo, interesses e necessidades singulares". No entanto, para que essa superação seja possível, cabe ao professor conhecer bem o seu aluno e buscar meios para tornar a aprendizagem significativa.

Castrogiovanni (2009, p. 13), afirma que "existe ainda pouca aproximação da escola com a vida, com o cotidiano dos alunos. [...] A vida fora da escola é cheia de mistérios, emoções, desejos, fantasias, como tendem a ser as ciências". Ainda de acordo com Castrogiovanni (2009), as escolas não apresentam essas características, o que as tornam transparentes e sem brilho. As mudanças vem ocorrendo na sociedade e com isso a educação também precisa ser repensada, pois o espaço e o tempo precisam de novas leituras e dimensões e cabe aqui a Geografia contribuir de forma significativa.

Bento (2015, p. 33), enfatiza a necessidade de "investir no processo de reflexão sobre a contribuição da Geografia na vida do jovem, em sua realidade imediata, em sua diversidade". Diante do exposto verifica-se a importância do papel do professor que precisa conhecer seus alunos para que a aprendizagem se torne significativa a partir do conhecimento prévio e até mesmo de sua própria realidade. Para Libâneo (2009, p. 137), "o trabalho docente deve ser contextualizado histórica e socialmente, isto é, articular ensino e realidade".

Na tentativa de articular ensino e realidade, Kaecher (2009), aponta caminhos metodológicos que podem nortear a prática docente, na qual se faz necessário ouvir os alunos, assim o docente terá mais material para preparar suas aulas, além do livro didático.

As pesquisas sobre o ensino de Geografia buscam superar o modelo conteudista, ainda presente na disciplina. Para Girotto (2015) essa superação pode ocorrer a partir do desenvolvimento do raciocínio geográfico dos alunos através da Geografia. Ressalta-se a importância da relação a ser construída entre professor e aluno, pois eles trazem consigo uma leitura das experiências da realidade e assim, Girotto (2015, p. 237), enfatiza que:

o professor poderá possibilitar aos alunos aperfeiçoarem as capacidades desenvolvidas além do muro da escola, ao mesmo tempo em que pode provocar o desenvolvimento de novas capacidades, principalmente a partir do diálogo com os conteúdos, conceitos e linguagens próprias da ciência geográfica.

Fazendo essa interação entre o conhecimento prévio dos alunos com o conhecimento científico o professor promoverá o ensino de Geografia que fará sentido para eles. Enfatizamos a importância do papel do professor como agente mediador da aprendizagem, porém não podemos deixar de enfatizar que o agente principal no processo de construção do conhecimento é o educando, conforme apresentado por Callai (2009, p. 101), "o processo de construção do conhecimento é, pois, uma tarefa que o estudante deve realizar, o nosso grande desafio como professores é oportunizar-lhe condições para tanto". E para que professores possam oportunizarem essas condições é necessário que tornem suas práticas reflexivas, para que tenham condições de avaliá-las e reformulá-las.

Segundo Guimarães (2015, p. 43), "ensinar bem Geografia, no atual contexto, requer do professor muitas habilidades, envolvimento, domínio de conhecimentos e busca de inovação". Qualquer ação que envolve o processo de ensino aprendizagem requer responsabilidade, dedicação e principalmente o domínio do campo do saber por parte dos professores.

No entanto, no que tange à formação de professores, falta investimentos na formação inicial e continuada de professores. As Diretrizes Curriculares Nacionais da Educação Básica (2013, p. 173) destacam que "a formação de professores não pode ser dissociada da valorização profissional, tanto no que diz respeito a uma remuneração mais digna, quanto à promoção da adequação e melhoria das condições de trabalho". Mesmo diante da realidade que presenciamos é importante ressaltar que a formação continuada de professores se faz necessária, pois é através dela que poderá refletir as práticas e realizar uma autoavaliação constante destas, mesmo que sejamos profissionais experientes.

Outra questão que merece atenção é em relação à metodologia utilizada no ensino de Geografia,

ParaOnde!?, Porto Alegre, v.10, n.2, p.103-110, 2018. Edição Especial com artigos publicados originalmente na XII ENANPEGE http://seer.ufrgs.br/paraonde 
pois de acordo com Vilhena (2015, p. 191),

o professor deve estar preparado para educar em um mundo globalizado, com novas tecnologias, mas ainda há a constatação de que, muitas vezes, os procedimentos e as metodologias adotados pelos professores não contribuem para tornar a aprendizagem prazerosa e significativa.

o

Mais do que estar preparado, o professor de Geografia deve estar sempre buscando diferenciar suas formas de trabalhar os conteúdos, podendo este utilizar as ferramentas tecnológicas para diversificar suas aulas, trabalhar o olhar do aluno através de observação com aula campo, dentre outras. Castellar (2015, p. 195) afirma que "repensar as práticas docentes e compreender as atividades como estratégia de aprendizagem favorece uma metodologia". A partir do momento em que o docente começa a refletir acerca de suas práticas e busca readequá-las a fim que todos os alunos, ou, pelo menos, a sua maioria aprendam o conteúdo ele vai inovando e consequentemente possibilita a aplicação de novas metodologias.

A partir de novas propostas didáticas e metodologias diferenciadas desperta-se o interesse dos jovens pelo ensino e possibilita uma relação mais afetiva entre professor e aluno, favorecendo na aprendizagem. Relacionar a teoria com a prática potencializa o ensino e a aprendizagem. Neste caso, o professor também aprende e em outros momentos pode partilhar de suas experiências com outros colegas de profissão. Castellar (2015, p. 195), aponta que "para um projeto inovador, a sala de aula não basta".

Pinheiro (2015), discorre que na área da educação temos a didática que vem se preocupando em questões referentes a formação dos professores e se existe uma didática específica para a Geografia esta deve estar evidente na organização do currículo. Várias mudanças vem acontecendo no cenário da educação brasileira, principalmente nas questões que envolvem o currículo, porém ainda distante de contemplar um currículo ideal.

Nesta abordagem, Callai (2015, p. 225), afirma que "o currículo escolar não é neutro, mas, ao ser resultado de escolhas, é ligado a interesses bem determinados". 0 que determina esses interesses são: a organização escolar, os professores, os alunos, o local no qual a escola está inserida, entre outros. Sobre o currículo de Geografia, Pérez (2015, p. 17) diz que "en todo caso, los currículos no siempre son restrictivos, y las potencialidades educativas de la Geografía para formar ciudadanos activos han tenido su reflejo también en los discursos curriculares".

De acordo com Melo (2010, p. 149), "o currículo passou a ser problematizado para além do campo psicopedagógico. Foi dissecado em suas filigranas com as esferas políticas, econômicas e socioculturais". Dessa forma o currículo baseia-se nas experiências e conhecimentos dos alunos em seu cotidiano escolar. Não podemos pensar o currículo estático como antigamente, pois ainda de acordo com Silva (2010, p. 150),

currículo é lugar, espaço, território. 0 currículo é relação de poder. 0 currículo é trajetória, viagem, percurso. 0 currículo é autobiografia, nossa vida, curriculum vitae: no currículo se forja nossa identidade. 0 currículo é texto, discurso, documento. 0 currículo é documento de identidade.

A partir dessa concepção podemos então entender o currículo como um instrumento de valores constituído a partir de um espaço-tempo social e cultural. No entanto, o que se percebe é um currículo real ainda muito distante do ideal, pois as Diretrizes Curriculares Nacionais vem propondo um currículo interdisciplinar, porém o que percebemos é cada professor trabalhando seus conteúdos de forma isolada.

\section{Caminhos Metodológicos}

Para o desenvolvimento da pesquisa se faz necessário que definamos quais os caminhos a percorrer para atingirmos os objetivos propostos. Para isso, precisamos buscar pistas para

\footnotetext{
Para0nde!?, Porto Alegre, v.10, n.2, p.103-110, 2018. Edição Especial com artigos publicados originalmente na XII ENANPEGE
} http://seer.ufrgs.br/paraonde 
alcançarmos as respostas ao nosso questionamento inicial. Buscamos como caminho metodológico a abordagem qualitativa devido sua relevância, na qual Flick $(2009$, p. 20), afirma que "a pesquisa qualitativa é de particular relevância ao estudo das relações sociais devido à pluralização das esferas da vida".

Dentro das várias técnicas de se desenvolver uma pesquisa qualitativa, podemos destacar segundo Oliveira (2011, p. 29) as seguintes: "entrevistas, observações, análise de conteúdo, estudo de caso e estudos etnográficos. Neste, contexto, a pesquisa será realizada em três etapas a saber: a) estudo bibliográfico, montagem dos questionários e roteiro de entrevista; b) pesquisa de campo e c) análise e discussão dos dados coletados.

A partir do momento em que estivermos em posse dos dados coletados, se faz necessário a análise dos pontos mais relevantes dos achados da pesquisa e confrontarmos com os principais autores que discutem o tema.

O tema é relevante, pois é importante buscarmos compreender o real sentido do ensino de Geografia e como essa ciência pode contribuir para a formação social destes jovens.

\section{Resultados Preliminares e Considerações finais}

A realização da análise bibliográfica sobre a primeira etapa da pesquisa, instiga a refletir sobre os jovens e o ensino de Geografia, pois há evidencia sobre a necessidade de conhecer quem são esses jovens que estão presentes no dia a dia em sala de aula por parte dos professores, assim a aprendizagem se torna significativa.

Para se construir um ensino de Geografia com qualidade, que seja significativo e criativo, depende da formação do professor, dos programas de formações continuadas, de um currículo que atenda às necessidades dos educandos, entre outros.

É importante destacar a necessidade do professor ser criativo e estar sempre buscando inovar suas aulas, no entanto, não é fácil essa tarefa de procurar inovar a prática em sala de aula, pois exige tempo e dedicação, porém professores vem desenvolvendo trabalhos relevantes, mesmo com sobrecarga de trabalho.

Diante da importância do currículo escolar, é necessário a ampliação das discussões sobre ele dentro das escolas a fim de construir um currículo ideal que contemple uma aprendizagem significativa para nossos jovens estudantes.

Quanto ao local de desenvolvimento da pesquisa apresentamos algumas informações inciais. De acordo com as informações do Plano de Desenvolvimento Institucional (PDI- 2015-2019), a Rede Federal de Educação Profissional, Científica e Tecnológica teve seu início em 29 de setembro de 1909, por meio do Decreto no 7.566 que criou dezenove Escolas de Aprendizes Artífices, durante o governo do Presidente Nilo Peçanha. Estas se destacaram no contexto educacional brasileiro ao longo do tempo pela excelência em qualidade na formação profissional.

A partir dessas unidades de ensino, foram criadas as Escolas Técnicas Federais (ETF's), Escolas Agrotécnicas Federais (EAFA's) e Centros Federais de Educação Tecnológica (CEFET's), hoje (a maioria) denominados Institutos Federais de Educação, Ciência e Tecnologia a partir da implantação da Lei no 11.892 de 29 de Dezembro de 2008, equiparando-os às universidades federais.

A referida lei, adiciona ainda, o desenvolvimento de programas de extensão e de divulgação científica e tecnológica, estimula a pesquisa, a produção cultural e a extensão vinculada à responsabilidade social e o vínculo direto com a melhoria do ensino médio. Estabelece o mínimo de $50 \%$ das vagas para cursos técnicos integrados de nível médio, 20\% para as licenciaturas e 30\% para outras ofertas.

O Campus Porto Nacional nasceu na conjuntura da expansão da Rede Federal de Educação, Ciência e Tecnologia, regulamentado pela portaria no. 102 de 29 de Janeiro de 2010, do Ministério da Educação publicada no Diário Oficial da União de 1ำ de fevereiro de 2010, no qual recebe autorização para seu funcionamento.

A implantação de um Campus do IFTO no município de Porto Nacional, partiu das considerações e reivindicações do setor produtivo e, principalmente, do setor público do município e mesorregião. Portanto, atende a um dos objetivos postos na lei de criação dos institutos: possibilitar à região, por

Para0nde!?, Porto Alegre, v.10, n.2, p.103-110, 2018. Edição Especial com artigos publicados originalmente na XII ENANPEGE http://seer.ufrgs.br/paraonde 
meio da oferta de cursos técnicos profissionais e profissionalizantes, de cursos superiores, inclusive de formação de professores, o atendimento às necessidades locais em favorecimento ao desenvolvimento socioeconômico local e regional.

Apesar de ter recebido a autorização para funcionamento em fevereiro de 2010, o Campus teve o início de suas atividades somente em 2 de agosto do ano de 2010, e oferecia os seguintes cursos: a) Curso Técnico em Informática e Técnico em Logística - subsequente ao Ensino Médio; b) Curso Superior de: Licenciatura em Computação e Tecnologia em Logística. Em 2012, o Campus também passou a oferecer o Curso Técnico em Meio Ambiente integrado ao ensino médio e atualmente conta com mais dois Cursos: a) Curso Técnico em Administração e b) Curso Técnico em Informática para Internet, ambos integrado ao ensino médio.

A pesquisa segue atenta as mudanças e transformações da escola no momento atual e segue também em busca dos sentidos do ensino de Geografia para os estudos do IFTO.

\section{Referências}

BENTO, Izabella Peracini. A cultura geográfica de jovens escolares. In: CAVALCANTI, Lana; CHAVEIRO, Eguimar F.; PIRES, Lucineide Mendes (orgs.). A Cidade e Seus Jovens. Goiânia: Ed. da PUC, 2015.

BRASIL. Diretrizes Curriculares Nacionais Gerais da Educação Básica. Ministério da Educação Básica. Secretaria de Educação Básica. Diretoria de Currículos e Educação Integral. Brasília: MEC, SEB, DICEI, 2013.

CALLAI, Helena Copetti. Estudar o lugar para compreender o mundo. In: CASTROGIOVANNI, Antonio Carlos; CALLAI, Helena Copetti; KAECHER, Nestor André (orgs.). Ensino de Geografia: práticas e textualizações no cotidiano. 7̣a ed. Porto Alegre: Editora Mediação, 2009.

Temas e conteúdos no ensino de geografia. In: RABELO, Kamila Santos de Paula; BUENO, Míriam Aparecida (orgs.). Currículo, políticas públicas e ensino de geografia. Goiânia: Ed. da PUC Goiás, 2015.

CASSAB, Clarice. Da casa para a rua: a dimensão espacial da juventude. In: CAVALCANTI, Lana; CHAVEIRO, Eguimar F.; PIRES, Lucineide Mendes (orgs.). A Cidade e Seus Jovens. Goiânia: Ed. da PUC, 2015.

Contribuição à construção das categorias jovem e juventude: uma introdução. Locus: revista de história, Juiz de Fora, v. 17, n.02, p. 145-159, 2011.

CASTELLAR, Sônia. Ensinar Geografia por meio da cartografia escolar: raciocínio espacial. In: BUENO, Míriam Aparecida; RABELO, Kamila Santos de Paula (orgs.). Currículo, Políticas Públicas e Ensino de Geografia. Goiânia: Ed. da PUC, 2015.

CASTROGIOVANNI, Antônio Calros. Apreensão e compreensão do espaço geográfico. In: ; CALLAI, Helena Copetti; KAECHER, Nestor André (orgs.). Ensino de Geografia: práticas e textualizações no cotidiano. 7aㅡ ed. Porto Alegre: Editora Mediação, 2009.

CAVALCANTI, Lana de Souza. Jovens escolares e sua geografia: práticas espaciais e percepção no/do cotidiano da cidade. In: CAVALCANTI, Lana de Souza; CHAVEIRO, Eguimar Felício; PIRES, Lucineide Mendes (orgs.). A Cidade e Seus Jovens. Goiânia: Ed. da PUC, 2015.

O ensino de geografia na escola. Campinas, São Paulo: Papirus, 2012.

A geografia escolar e a cidade: ensaios sobre o ensino de geografia para a vida urbana cotidiana.

Campinas: Papirus, 2008.

ParaOnde!?, Porto Alegre, v.10, n.2, p.103-110, 2018. Edição Especial com artigos publicados originalmente na XII ENANPEGE http://seer.ufrgs.br/paraonde 
DAYRELL, Juarez. A escola "faz" as juventudes? Reflexões em torno da socialização juvenil. Educação $e$ Sociedade, Campinas, vol. 28, n. 100 - Especial, p. 1105-1128, out. 2007.

FLICK, Uwe. Introdução à Pesquisa Qualitativa. Tradução de Joice Elias Costa. $3^{a}$ ed. Porto Alegre: Artemed, 2009.

GIROTTO, Eduardo Donizeti. Formando leitores do mundo: algumas considerações sobre o ensino de Geografia no mundo contemporâneo. Boletim Campineiro de Geografia, Campinas, v. 5, n. 2, p. 231-247, 2015.

GUIMARÃES, Iara Vieira. Questões sobre a formação de professores de geografia. In: BUENO, Míriam Aparecida; RABELO, Kamila Santos de Paula (orgs.). Currículo, Políticas Públicas e Ensino de Geografia. Goiânia: Ed. da PUC, 2015.

KAECHER, Nestor André. Geografizando o jornal e outros cotidianos: práticas em geografia para além do livro didático. In: CASTROGIOVANNI, Antonio Carlos; CALLAI, Helena Copetti; KAECHER, Nestor André (orgs.). Ensino de Geografia: práticas e textualizações no cotidiano. 7ํㅗ ed. Porto Alegre: Editora Mediação, 2009.

KEHL, Maria Rita. A juventude como sintoma da cultura. In: NOVAES, Regina; VANNUCHI, Paulo (orgs.). Juventude e Sociedade: trabalho, educação, cultura e participação. São Paulo: Fundação Perseu Abramo, 2004.

LIBÂNEO, José Carlos. Democratização da Escola Pública. A pedagogia crítico-social dos conteúdos. 16ª edição. São Paulo: Coleção Educar 1. Loyola, 2009.

MELO, José Wilson Rodrigues. Currículo e diversidade cultural: a ressignificação dos centros escolares. In: SANTOS, Jocyléia Santana dos; ZAMBONI, Ernesta. Potencialidades Investigativas da Educação. Goiânia: Ed. da PUC, 2010.

OLIVEIRA, Victor Hugo Nedel. Somos Jovens: o ensino de geografia e a escuta da juventude. 2015. $126 \mathrm{f}$. Dissertação (Mestrado em Geografia) - Universidade Federal do Rio Grande do Sul. Instituto de Geociências, Porto Alegre, $2015 . \quad$ Disponível em: http://bdtd.ibict.br/vufind/Record/URGS_671256d28c5e851ce647a6d7b11d9253. Acesso em: 20 mar. 2016.

OLIVEIRA, Maria Marly de. Como fazer projetos, relatórios, monografias, dissertações e teses. 5⿳亠丷a ed. Rio de Janeiro: Elsevier, 2011.

PÉREZ, Francisco Florentino Garcia. ¿Puede la enseñanza de la geografía promover educación ciudadana? In: BUENO, Míriam Aparecida; RABELO, Kamila Santos de Paula (orgs.). Currículo, Políticas Públicas e Ensino de Geografia. Goiânia: Ed. da PUC, 2015.

PINHEIRO, Antônio Carlos. Reformas curriculares, políticas públicas e ensino de geografia: reflexões, experiências e práticas. In: BUENO, Míriam Aparecida; RABELO, Kamila Santos de Paula (orgs.). Currículo, Políticas Públicas e Ensino de Geografia. Goiânia: Ed. da PUC, 2015.

PDI - Plano de Desenvolvimento Institucional (2015- 2019). Disponível em: http://portal.ifto.edu.br/ifto/colegiados/consup/documentos-aprovados/pdi/plano-dedesenvolvimento-institucional-2015-2019.pdf/view. Acesso em: 19/05/2017.

SILVA, Tomaz Tadeu da. Documentos de indentidade: uma introdução às teorias do currículo. $3^{\mathrm{a}}$ ed. Belo Horizonte: Autêntica, 2010. 
VILHENA, Jerusa de Moraes. As metodologias ativas e o ensino de geografia: um olhar sobre algumas produções científicas. In: BUENO, Míriam Aparecida; RABELO, Kamila Santos de Paula (orgs.). Currículo, Políticas Públicas e Ensino de Geografia. Goiânia: Ed. da PUC, 2015. 